\title{
Gallic acid as a selective anticancer agent that induces apoptosis in SMMC-7721 human hepatocellular carcinoma cells
}

\author{
GUOJUN SUN $^{1 *}$, SHUQIN ZHANG $^{1}$, YANRU XIE $^{2 *}$, ZIYU ZHANG $^{1}$ and WENJING ZHAO ${ }^{1}$ \\ ${ }^{1}$ Central Laboratory, Hepatobiliary Disease Hospital of Jilin Province, Changchun, Jilin 130062; \\ ${ }^{2}$ Department of Medical Oncology, Lishui Central Hospital, Lishui, Zhejiang 323000, P.R. China
}

Received October 28, 2014; Accepted August 20, 2015

DOI: $10.3892 / 01.2015 .3845$

\begin{abstract}
Gallic acid (3,4,5-trihydroxybenzoic acid; GA) is a naturally occurring plant polyphenol, isolated from water caltrop, which has been reported to exert anticancer effects. The present study investigated the antiproliferative effects of GA on the HepG2 and SMMC-7721 human hepatocellular carcinoma (HCC) cell lines using MTT and colony formation assays. In particular, the underlying mechanism of GA-induced apoptosis in SMMC-7721 cells was studied in vitro by flow cytometry and western blotting. The results of the present study indicated that GA was capable of inhibiting the proliferation of HepG2 and SMMC-7721 cells in a timeand dose-dependent manner, as well as inducing the apoptosis of SMMC-7721 cells. GA induced caspase-3, caspase-9 and reactive oxygen species activity, elevated the expression of apoptosis regulator $\mathrm{Bcl}-2$-like protein 4 and reduced the mitochondrial membrane potential in SMMC-7721 cells. When compared with HL-7702 normal human hepatocytes, GA demonstrated selective toxicity for HCC cells. In conclusion, GA is able to induce apoptosis in SMMC-7721 cells in vitro via mitochondrial-mediated pathways, and may possess the potential to be a novel therapeutic compound for use in the treatment of HCC.
\end{abstract}

\section{Introduction}

Hepatocellular carcinoma (HCC) is a primary malignancy of the liver, which is associated with high morbidity and mortality rates (1). Worldwide, HCC is the fifth most common type of cancer, and the third leading cause of cancer-associated mortality (2). It has been reported that

Correspondence to: Dr Wenjing Zhao, Central Laboratory, Hepatobiliary Disease Hospital of Jilin Province, 2218 Jingyang Road, Luyuan, Changchun, Jilin 130062, P.R. China E-mail: xingyuewj@163.com

*Contributed equally

Key words: hepatocellular carcinoma, apoptosis, mitochondrial pathway, gallic acid, plant polyphenol
Asian countries account for $75-80 \%$ of the $\sim 650,000$ cases of HCC that are annually reported worldwide, and China alone accounts for $55 \%$ of global HCC cases $(3,4)$. At present, HCC is the second leading cause of cancer-associated mortality in China (5). Currently, a range of adverse side-effects, including toxicity and drug resistance, limit the efficacy of the clinical drugs used in the treatment of HCC, although substantial advances have been made with regard to chemotherapeutic treatments (6). However, an urgent need to identify more effective chemotherapeutic agents for the treatment of HCC remains $(7,8)$.

The screening of safe and effective anti-tumor compounds from Traditional Chinese Medicine is currently a hotspot of research, and a number of effective components isolated from plants have been revealed to possess significant cytotoxicity against certain cancer cells (9). Gallic acid (3,4,5-trihydroxybenzoic acid; GA) is a naturally occurring plant polyphenol, isolated from water caltrop $(10,11)$. GA is notable due to its natural and marked antioxidative, antiallergenic, anti-mutagenic, anticarcinogenic, antiviral, antibacterial and anti-inflammatory activities (12-15). Previous studies have demonstrated that GA is capable of selectively inducing apoptosis in certain tumor cell lines, including HL-60RG, HeLa, dRLh-84, PLC/PRF/5 and KB cells (16-19). In addition, GA has a significant role in the prevention of malignant transformation and development of cancer in vivo (20). To the best of our knowledge, to date, there have been limited reports concerning the effects of GA on human HCC. Therefore, further studies are required in order to evaluate the biological function and roles of GA in HCC.

In the present study, the anti-proliferative effects of GA on HepG2 and SMMC-7721 human HCC cell lines were investigated.

\section{Materials and methods}

Materials. GA (purity, 99.5\%; melting point, $251^{\circ} \mathrm{C}$ ), MTT, dimethyl sulfoxide (DMSO), rhodamine (RH)-123 and 2,7-dichlorfluorescein-diacetate were obtained from Sigma-Aldrich (St. Louis, MO, USA). Dulbecco's modified Eagle medium (DMEM), RPMI-1640 and fetal bovine serum (FBS) were purchased from Gibco Life Technologies (Carlsbad, CA, USA). Penicillin and streptomycin sulfate were purchased from GE Healthcare Life Sciences (Logan, 
UT, USA). Mouse anti-B-cell lymphoma (Bcl)-2, apoptosis regulator Bcl-2-like protein 4 (Bax) and cytochrome $c$ immunoglobulin $\mathrm{G}(\mathrm{IgG})$ monoclonal antibodies and anti- $\beta$-actin IgG polyclonal antibody were purchased from BD Biosciences (San Jose, CA, USA). Horseradish peroxidase-conjugated anti-mouse IgG was purchased from OriGene Technologies, Inc. (Beijing, China). The acridine orange staining kit, Annexin $\mathrm{V}$ binding apoptosis assay kit and caspase activity assay kit were purchased from Nanjing KeyGen Biotech Co., Ltd. (Nanjing, China). GA was dissolved in DMSO to produce a stock solution $(10 \mathrm{mg} / \mathrm{ml})$, and diluted to various concentrations with double-distilled water containing $10 \%$ DMSO.

Cell culture. The HepG2 and SMMC-7721 human HCC cell lines were obtained from the Cell Bank of the Chinese Academy of Science (Beijing, China). Cells were cultured in DMEM medium containing 10\% FBS, $100 \mathrm{U} / \mathrm{ml}$ penicillin and $100 \mu \mathrm{g} / \mathrm{ml}$ streptomycin sulfate. The HL-7702 human normal hepatocyte cell line was obtained from the Chinese Academy of Science Type Culture Collection (Shanghai, China) and incubated in RPMI-1640 medium supplemented with $10 \%$ FBS. All cells were incubated at $37^{\circ} \mathrm{C}$ in a humidified incubator (Thermo Fisher Scientific, Waltham, MA, USA) in an atmosphere of $5 \% \mathrm{CO}_{2}$. Cells were detached from the monolayer using $0.25 \%$ trypsin (Sigma-Aldrich) for $5 \mathrm{~min}$ once cells had grown to near confluence.

Cell viability assay and half maximal inhibitory concentration $\left(I C_{50}\right)$ measurement. Cell viability was measured using MTT assays (21). HepG2, SMMC-7721 and HL-7702 cells were seeded at a density of $2 \times 10^{4}$ cells/well in 96-well plates and allowed to adhere for $24 \mathrm{~h}$. Subsequently, the medium was replaced with $200 \mu 1$ complete medium (DMEM or RPMI-1640 medium supplemented with $10 \%$ FBS), supplemented with various concentrations of GA $(0,6.25,12.5,25.0,50.0$ and $100.0 \mu \mathrm{g} / \mathrm{ml})$. Cells were incubated for 24,48 and $72 \mathrm{~h}$, and following incubation, $20 \mu \mathrm{l} \mathrm{MTT}(5 \mathrm{mg} / \mathrm{ml})$ was added to each well. Cells were incubated for an additional $4 \mathrm{~h}$, the medium was removed, the formazan crystals were dissolved in $150 \mu \mathrm{l}$ DMSO and the absorbance values were measured at a wavelength of $490 \mathrm{~nm}$ using a microplate reader (Synergy ${ }^{\mathrm{TM}} \mathrm{H} 4$ Hybrid Microplate Reader; RayBiotech, Norcross, GA, USA). The relative cell viability $\mathrm{IC}_{50}$ (concentration inducing $50 \%$ cytotoxicity) value following $48 \mathrm{~h}$ of treatment was extrapolated from linear regression analysis of experimental optical density (OD) data using WinNonlin software (version 5.2; Pharsight Corp., Princeton, NJ, USA) (22). The experiment was repeated in triplicate.

Colony formation assay. To investigate the survival of cells treated with GA, colony formation assays were performed as previously described (23). HepG2 and SMMC-7721 cells were seeded (300 cells/well) into a 24 -well plate and allowed to adhere for $24 \mathrm{~h}$. Cells were incubated in culture medium containing GA $(0,2.0,4.0,6.0,8.0$ and $10.0 \mu \mathrm{g} / \mathrm{ml})$ for $\sim 6$ days. Following incubation, the cells were fixed with methanol (Beijing Dingguo Changsheng Biotech Co., Ltd., Beijing, China) and stained using a Giemsa staining kit (Nanjing KeyGen Biotech Co., Ltd.) and colonies (>50 cells) were counted using an Olympus IX71 inverted microscope (Olympus Corp., Toyko, Japan).

Giemsa staining. Apoptotic morphology was detected using an Annexin V binding apoptosis kit, according to the manufacturer's instructions (Nanjing KeyGen Biotech Co., Ltd.). In brief, 5x10 $0^{5}$ MMC-7721 cells/well were seeded into a 6-well plate containing a cover slip, and cultured overnight at $37^{\circ} \mathrm{C}$ in a humidified incubator.. Cells were treated with $0,6.25,12.5$ and $25.0 \mu \mathrm{g} / \mathrm{ml} \mathrm{GA}$ for $48 \mathrm{~h}$. The treated cells were washed with phosphate-buffered saline (PBS; Beijing Dingguo Changsheng Biotech Co., Ltd.), fixed in 10\% paraformaldehyde (Beijing Dingguo Changsheng Biotech Co., Ltd.) for $10 \mathrm{~min}$ and stained with reagent I (Giemsa) from the kit. Typical apoptotic changes to the nuclei were observed using light microscopy (CHK-213; Olympus Corp., Tokyo, Japan), and apoptotic cells were identified according to criteria from a previous study (24).

Acridine orange staining. Apoptotic morphology was detected using acridine orange staining, according to the manufacturer's instructions. Briefly, 5x105 SMMC-7721 cells/well were seeded into a 6-well plate and cultured overnight. Cells were treated with $0,25.0$ and $50.0 \mu \mathrm{g} / \mathrm{ml} \mathrm{GA}$ for $48 \mathrm{~h}$. Treated cells were subsequently harvested and stained with acridine orange $(100 \mu \mathrm{g} / \mathrm{ml})$ for $15 \mathrm{~min}$ in the dark. Any morphological changes to the nuclei were observed using fluorescence microscopy (Eclipse TS100, Nikon Corp., Tokyo, Japan).

DNA fragmentation analysis. In order to evaluate oligonucleosomal fragmentation, genomic DNA was extracted and examined using agarose gel electrophoresis as previously described (25). SMMC-7721 cells $\left(5 \times 10^{5}\right.$ cells/well) were seeded into 6-well plates and treated with various concentrations of GA $(0,6.25,12.5$ and $25.0 \mu \mathrm{g} / \mathrm{ml})$ for $48 \mathrm{~h}$. Subsequently, the cells were collected and the DNA from treated and untreated cells was extracted using a DNA ladder sample preparation kit (Nanjing KeyGen Biotech Co., Ltd.), according to the manufacturer's instruction. DNA samples were separated using 2\% agarose gel electrophoresis (Beijing Dingguo Changsheng Biotech Co., Ltd.) at $50 \mathrm{~V}$ for $3 \mathrm{~h}$, and subsequently visualized with ethidium bromide using a Gel Documentation system (Far Gene Pouyesh, Tehran, Iran).

Annexin V-fluorescein isothiocyanate (FITC)/propidium iodide (PI) double-staining analysis. The proportion of apoptotic cells was measured using Annexin V-FITC/PI double staining, according to the manufacturer's instructions. SMMC-7721 cells $\left(5 \times 10^{5}\right.$ cells/well) were seeded into a 6 -well plate and cultured overnight. Cells were treated with GA ( 0 , $6.25,12.5$ and $25.0 \mu \mathrm{g} / \mathrm{ml}$ ) for $48 \mathrm{~h}$, subsequently harvested and washed twice with ice-cold PBS, and treated according to the manufacturer's instructions. Following harvesting and washing, cells were immediately analyzed using flow cytometry (FCM; COULTER ${ }^{\circledR}$ EPICS $^{\circledR}$ XL $^{\text {TM }}$ Flow Cytometer; Beckman Coulter, Inc., Brea, CA, USA).

Caspase activity assay. The levels of caspase-3, -8 and -9 activity were measured using the caspase activity assay kit according to the manufacturer's instructions. Briefly, following 
GA treatment $(0,6.25,12.5,25.0$, and $50.0 \mu \mathrm{g} / \mathrm{ml})$ for $48 \mathrm{~h}$, $\sim 3 \times 10^{5}$ SMMC-7721 cells were harvested and washed twice with PBS, and subsequently treated with the caspase activity assay kit according to the manufacturer's instructions. Data were obtained in triplicate and expressed as the mean \pm standard deviation. The activity of caspase was normalized and expressed as $\mathrm{OD}_{\text {test }} / \mathrm{OD}_{\text {control }} \mathrm{x} 100 \%$.

Mitochondrial membrane potential (MMP) analysis. The change in MMP in SMMC-7721 cells was analyzed by flow cytometry using RH-123 staining (26). Briefly, following $48 \mathrm{~h}$ of GA treatment $(0,6.25,12.5$ and $25.0 \mu \mathrm{g} / \mathrm{ml}), \sim 3 \times 10^{5}$ SMMC-7721 cells were harvested and stained with PBS containing $3 \mu \mathrm{g} / \mathrm{ml} \mathrm{RH}-123$ at $37^{\circ} \mathrm{C}$, for $30 \mathrm{~min}$ in the dark. Stained cells were subsequently washed with ice-cold PBS and the RH-123 fluorescence was detected by FCM.

Detection of reactive oxygen species (ROS). The production of ROS in SMMC-7721 cells was detected by FCM using dichloro-dihydro-fluorescein diacetate (DCFH-DA; Sigma-Aldrich) as a probe according to previous methodology (27). Briefly, SMMC-7721 cells $\left(5 \times 10^{5}\right.$ cells/well) were seeded into a 6 -well plate and cultured overnight. Cells were treated with GA $(0,6.25,12.5$ and $25.0 \mu \mathrm{g} / \mathrm{ml})$ for $2 \mathrm{~h}$, and subsequently harvested, washed twice with PBS and incubated with $10 \mu \mathrm{M}$ DCFH-DA for $30 \mathrm{~min}$ at $37^{\circ} \mathrm{C}$. The intracellular ROS generation converted non-fluorescent DCFH-DA to the highly fluorescent compound 2,7-dichlorfluorescein (DCF). DCF fluorescence intensity was determined in 10,000 cells using FCM. The proportion of cells in the right quadrant with a higher intensity of DCF fluorescence represented the cells with increased ROS levels.

Western blotting. The expression levels of Bax, Bcl-2 and cytochrome $c$ proteins were measured by western blotting according to the standard protocol (28). SMMC-7721 cells $\left(2 \times 10^{6}\right)$ were seeded into a $10-\mathrm{cm}$ plate and cultured overnight. Following treatment with GA $(0,6.25$, 12.5 and $25.0 \mu \mathrm{g} / \mathrm{ml}$ ) for $48 \mathrm{~h}$, whole-cell protein or mitochondrial fractions were isolated using the protein extraction kit (Nanjing KeyGen Biotech Co., Ltd.). Protein concentration was measured using the bicinchoninic acid protein assay kit (Nanjing KeyGen Biotech Co., Ltd.). Protein $(50 \mu \mathrm{g})$ was separated using $12 \%$ SDS-PAGE with the Mini-PROTEAN ${ }^{\circledR}$ system (Bio-Rad Laboratories, Inc., Hercules, CA, USA) and subsequently transferred onto a polyvinylidene difluoride membrane (Gene Tech Biotechnology Co., Ltd., Shanghai, China). The membranes were incubated with the specific aforementioned antibodies (1:500 dilution) against Bax, $\mathrm{Bcl}-2$ and cytochrome $c$ for $2 \mathrm{~h}$ at $37^{\circ} \mathrm{C}$. Following washing with Tris-buffered saline and Tween 20, the membranes were incubated with peroxidase-conjugated $\operatorname{IgG}$ goat anti-mouse or anti-rabbit secondary antibody (1:1,000 dilution; OriGene Technologies, Inc.) for $30 \mathrm{~min}$ at $37^{\circ} \mathrm{C}$, respectively. Immunoreactive proteins were visualized using 3,3-diaminobenzidine staining. $\beta$-actin served as a control.

Statistical analysis. All experimental data are expressed as the mean \pm standard deviation, and reproducibility was confirmed in at least three separate experiments. Statistical analysis was

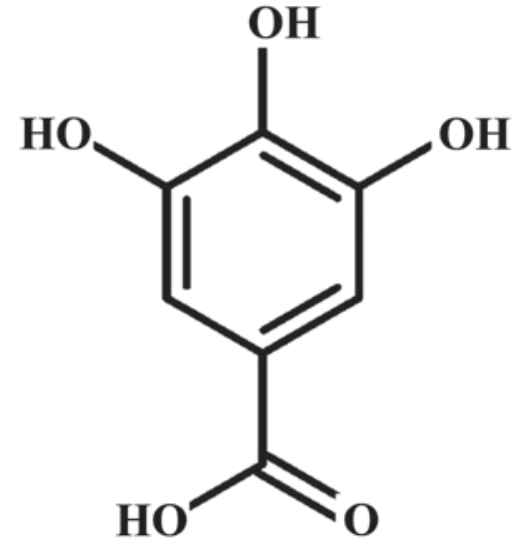

Figure 1. Chemical structure of gallic acid.

performed using SPSS version 13.0 (SPSS, Inc., Chicago, IL, USA).

\section{Results}

GA selectively inhibits the growth of HCC cells. Fig. 1 illustrates the chemical structure of GA. The present study initially investigated the cytotoxic effects of GA on HepG2 and SMMC-7721 cells by MTT assay. As demonstrated in Fig. 2A and B, the proliferation of HepG2 and SMMC-7721 cells was markedly decreased following GA treatment, in a dose- and time-dependent manner. The $\mathrm{IC}_{50}$ values of GA were $28.5 \pm 1.6 \mu \mathrm{g} / \mathrm{ml}$ for HepG2 cells and $22.1 \pm 1.4 \mu \mathrm{g} / \mathrm{ml}$ for SMMC-7721 cells at $48 \mathrm{~h}$. This indicated that GA effectively inhibited the proliferation of HepG2 and SMMC-7721 cells, and the anti-proliferative effect of GA on SMMC-7721 cells exceeded the anti-proliferative effect on HepG2 cells, with significantly lower $\mathrm{IC}_{50}$ values of GA for SMMC-7721 compared with HepG2 $(\mathrm{P}<0.05)$. As a control, the cytotoxic effects of GA on a HL-7702 human normal hepatocyte line were also investigated. As demonstrated in Fig. 2C, the $\mathrm{IC}_{50}$ value was $80.9 \pm 4.6 \mu \mathrm{g} / \mathrm{ml}$ for HL-7702 cells at $48 \mathrm{~h}$. This value was 3 -fold higher than the $\mathrm{IC}_{50}$ value observed in HCC cells, which indicated that GA was able to selectively inhibit the growth of HCC cells. Furthermore, the present study investigated the effects of GA on the survival rate of HepG2 and SMMC-7721 cells by colony formation assay. As indicated in Fig. 2D, GA treatment resulted in a significant inhibition in the colony formation ability of HepG2 and SMMC-7721 cells in a dose-dependent manner.

GA induces morphological changes and apoptosis in SMMC-7721 cells. To determine the mode of cell death observed, morphological changes in the nucleus of SMMC-7721 cells following GA treatment were analyzed using Giemsa and acridine orange staining. As demonstrated in Fig. 3, the plasma membrane, nuclear envelope and nucleolus were complete and distinct in untreated SMMC-7721 cells. By contrast, the nuclei of SMMC-7721 cells treated with GA (6.25, $12.5,25 \mu \mathrm{g} / \mathrm{ml}$ ) for $48 \mathrm{~h}$ exhibited condensed and fragmented chromatin, indicative of apoptosis.

The present study also investigated the induction of apoptosis in SMMC-7721 cells via the occurrence of DNA fragmentation. It was observed that DNA extracted from untreated 
A
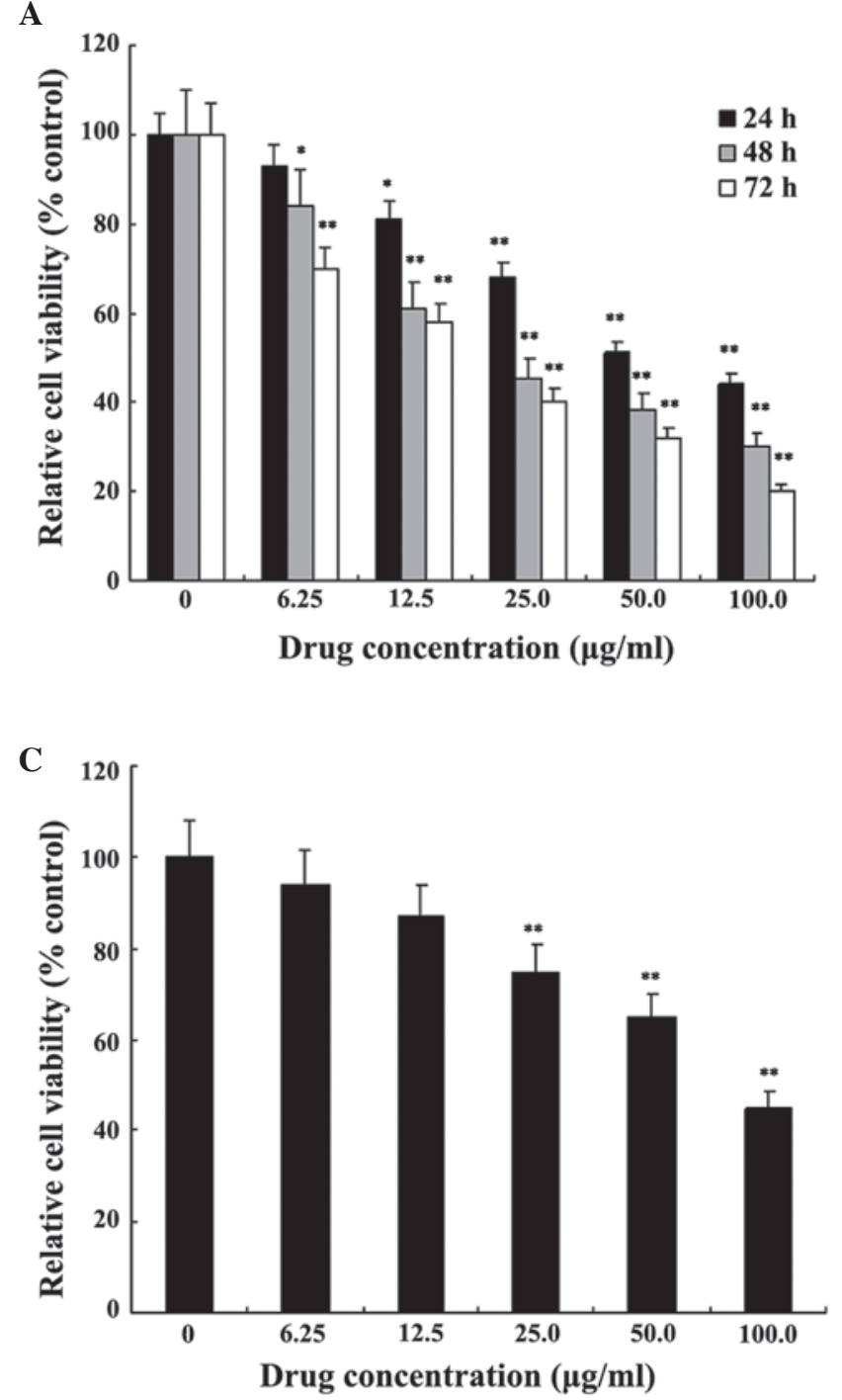

B

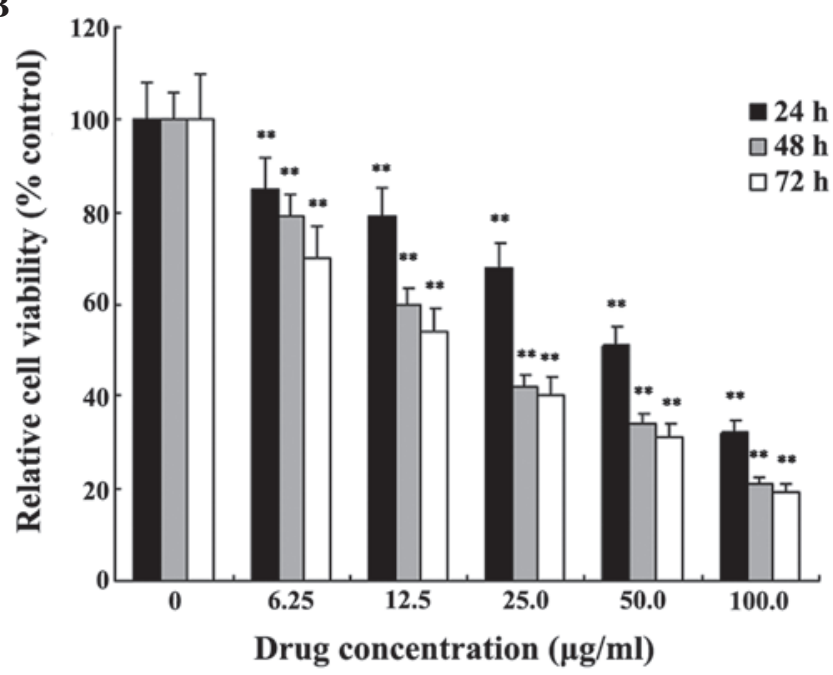

D

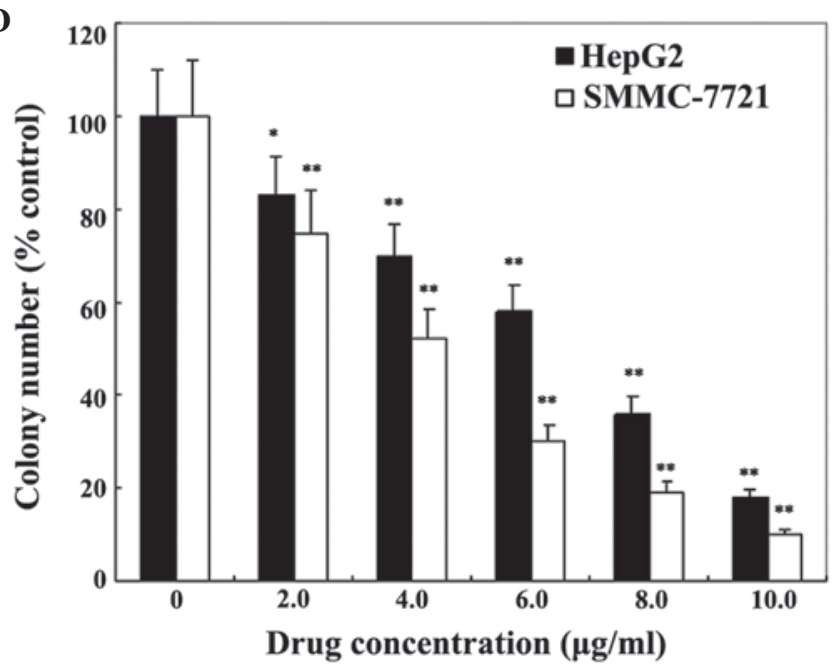

Figure 2. GA selectively inhibits the proliferation of hepatocellular carcinoma cells in a dose-dependent manner. Effect of GA treatment on the viability of (A) HepG2 cells (B) SMMC-7721 cells and (C) HL-7702 cells. (D) Effect of GA on the colony formation of SMMC-7721 and HepG2 cells. Data are expressed as the mean \pm standard deviation of three separate experiments. Significant differences from untreated cells are indicated, ${ }^{*} \mathrm{P}<0.05,{ }^{* *} \mathrm{P}<0.01 \mathrm{vs}$. control group. GA, gallic acid.

SMMC-7721 cells exhibited no fragmentation, while DNA from GA treated cells demonstrated DNA laddering, which occurred as a result of endonuclease action at sites between nucleosomes (Fig. 4). In order to confirm the apoptotic effect of GA on SMMC-7721 cells, Annexin-V FITC/PI apoptosis assays were performed. The results revealed that GA induced apoptosis in SMMC-7721 cells (Fig. 5). The early apoptotic cell proportions in the lower right quadrant $\left(\mathrm{FITC}^{+} / \mathrm{PI}^{-}\right)$were $11.8 \pm 0.8,17.7 \pm 0.7$ and $27.8 \pm 0.8 \%$ for SMMC-7721 cells treated with $6.25,12.5$ and $25.0 \mu \mathrm{g} / \mathrm{ml} \mathrm{GA}$, respectively. The late apoptotic or necrotic cell proportions in the upper right quadrant $\left(\mathrm{FITC}^{+} / \mathrm{PI}^{+}\right)$were $1.8 \pm 0.4$, $10.2 \pm 0.6$ and $19.2 \pm 0.5 \%$, respectively. These results suggest that GA partially inhibited the proliferation of SMMC-7721 cells via the induction of apoptosis.

GA upregulates the activity of caspase-3 and -9 in a dose-dependent manner. To assess whether the GA-induced apoptosis of SMMC-7721 cells was caspase-dependent, the catalytic activity of caspase- $3,-8$ and -9 was examined. The results (Fig. 6A and B) demonstrated that GA upregulated the activity of caspase-3 and caspase-9 in SMMC-7721 cells in a dose-dependent manner. When SMMC-7721 cells were treated with $12.5 \mu \mathrm{g} / \mathrm{ml} \mathrm{GA}$ for $48 \mathrm{~h}$, the relative activities of caspase-3 and -9 were increased 2.0- and 1.5-fold, respectively. When SMC-7721 cells were treated with $25 \mu \mathrm{g} / \mathrm{ml}$ GA for $48 \mathrm{~h}$, the relative activities of caspase- 3 and -9 were increased 3.0- and 2.5-fold, respectively. When SMMC-7721 cells were treated with $50.0 \mu \mathrm{g} / \mathrm{ml} \mathrm{GA}$ for $48 \mathrm{~h}$, the relative activities of caspase-3 and -9 were increased 3.0- and 2.0-fold, respectively. This decrease in activity compared with the cells treated with $25.0 \mu \mathrm{g} / \mathrm{ml} \mathrm{GA}$ may be due to the presence of more necrotic cells. However, the activity of caspase- 8 was not markedly altered compared with that of untreated cells (Fig. 6C).

GA induces a reduction of the MMP in SMMC-7721 cells. Caspase activation is primarily triggered by a change in MMP, and apoptosis is also associated with loss of the MMP in a number of cases. Therefore, the present study measured the MMP of 


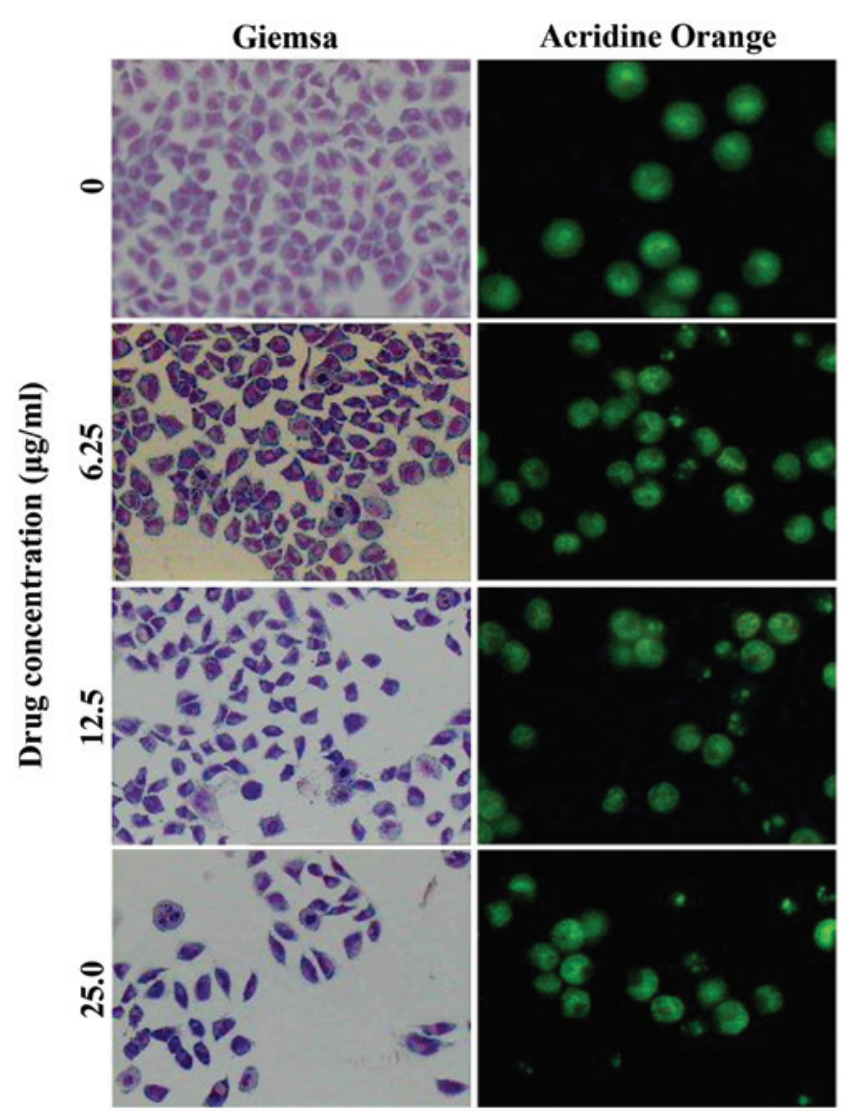

Figure 3. Gallic acid induces development of apoptotic morphology of SMMC-7721 cells (magnification, x200). Apoptotic morphological changes of SMMC-7721 cells were observed under light (left panels) or fluorescence (right panels) microscopy.

SMMC-7721 cells using RH-123 dye as marker, and flow cytometric analysis revealed depletion of the MMP. Untreated SMMC-7721 cells possessed intact plasma and a normal MMP, and the cell RH-123 fluorescence was $95.7 \pm 0.4 \%$. However, in SMMC-7721 cells treated with $6.25,12.5$ and $25.0 \mu \mathrm{g} / \mathrm{ml} \mathrm{GA}$ for $48 \mathrm{~h}$, the levels of RH-123 fluorescence were $86.5 \pm 1.4,77.1 \pm 2.2$ and $67.7 \pm 2.8 \%$, respectively; this fluorescence was statistically different from the untreated group $(\mathrm{P}<0.05$; Fig. 7A). The percentage of SMMC-7721 cells containing quenched RH-123 increased with increasing GA concentration, and the reduction in RH-123 levels indicated a loss of the MMP. These results revealed that GA induced mitochondrial depolarization and a reduction of the MMP in SMMC-7721 cells.

GA treatment enhances ROS generation. ROS generation may correspond with a reduction in the MMP, and ROS have been observed to be involved in the induction of apoptosis in a number of systems. In order to determine whether ROS production was involved in GA-induced apoptosis of SMMC-7721 cells, the present study detected the ROS levels in GA-treated SMMC-7721 cells using DCFH-DA. Flow cytometric analysis revealed that untreated SMMC-7721 cells possessed low levels of endogenous ROS $(2.6 \pm 0.2 \%)$, whereas treatment with GA significantly enhanced intracellular ROS levels. The levels of ROS generation reached $11.3 \pm 0.8,20.1 \pm 2.3$ and $47.4 \pm 2.8 \%$, when SMMC-7721 cells were treated with $6.25,12.5$ and $25.0 \mu \mathrm{g} / \mathrm{ml} \mathrm{GA}$, respectively, for $2 \mathrm{~h}$; this ROS

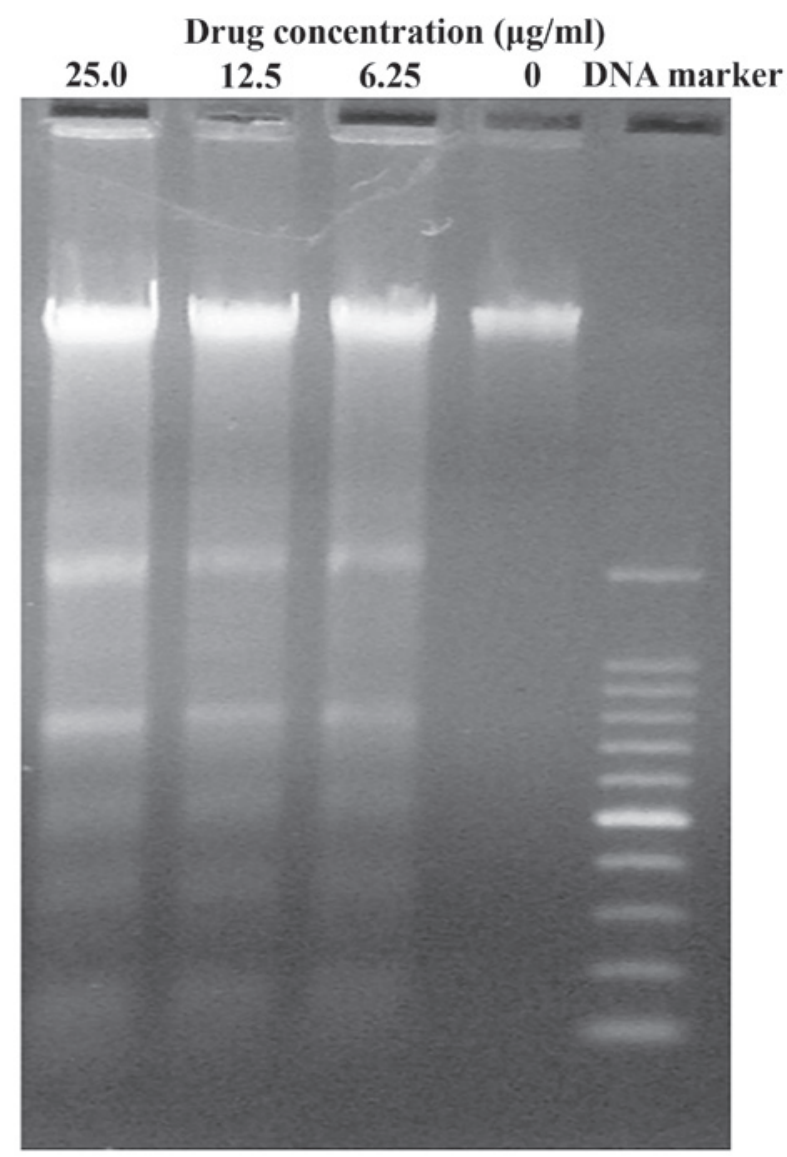

Figure 4. DNA fragment analysis of SMMC-7721 cells following treatment with various concentrations of gallic acid. DNA isolated from SMMC-7721 cells treated with $6.25,12.5$ and $25.0 \mu / \mathrm{ml} \mathrm{GA}$ for $48 \mathrm{~h}$, and then analyzed by agarose gel electrophoresis. GA induced DNA fragmentation.

generation was significantly different from the untreated group $(\mathrm{P}<0.05$; Fig. 7B). These results indicated that treatment with GA elevated intracellular ROS levels in SMMC-7721 cells.

GA treatment affects the expression of proteins associated with apoptosis. Mitochondria possess a critical role in caspase-dependent cell apoptosis, via the release of cytochrome $c$ (29). Bax is also known to be associated with mitochondrial function. Following translocation to the mitochondrial membrane, Bax initiates cytochrome $c$ release and subsequently activates caspase during apoptosis (30). In order to investigate whether cytochrome $c$, Bax and Bcl-2 expression were involved in the apoptosis of SMMC-7721 cells, the present study measured the cytochrome $c$ levels in the cytosol and mitochondria, and investigated Bax and Bcl-2 expression using western blotting. The results of these investigations revealed that Bcl-2 protein expression was downregulated and Bax expression was upregulated, and the levels of cytochrome $c$ in the cytosol were increased, accompanied by a reduction in the levels of cytochrome $c$ in mitochondria following treatment with various concentrations of GA for $48 \mathrm{~h}$ (Fig. 8).

\section{Discussion}

In Traditional Chinese Medicine, herbal plants and plant-derived medicines are frequently used (21). A number of phytochemicals 


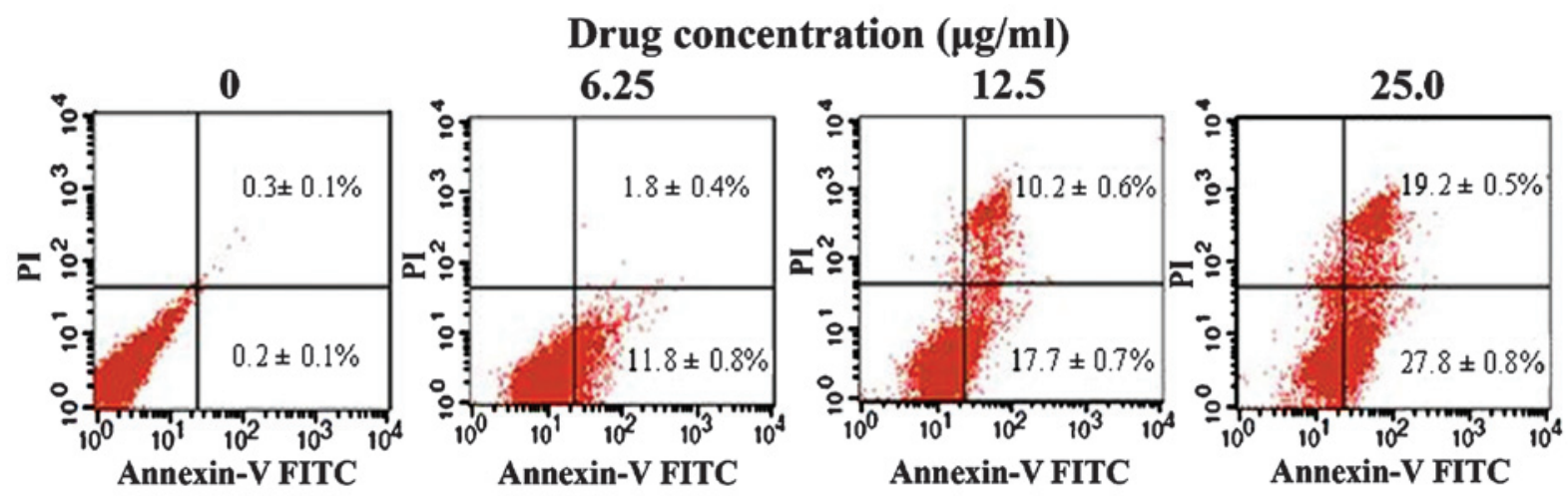

Figure 5. Flow cytometric analysis of SMMC-7721 cells following treatment with gallic acid. The extent of apoptosis induced in SMMC-7721 cells treated by $6.25,12.5$ and $25.0 \mu \mathrm{g} / \mathrm{ml} \mathrm{GA}$ for $48 \mathrm{~h}$ was measured by flow cytometry. Data from three independent experiments are shown, and values are presented as the mean \pm standard deviation. FITC, fluorescein isothiocyanate; PI, propidium iodide.

A

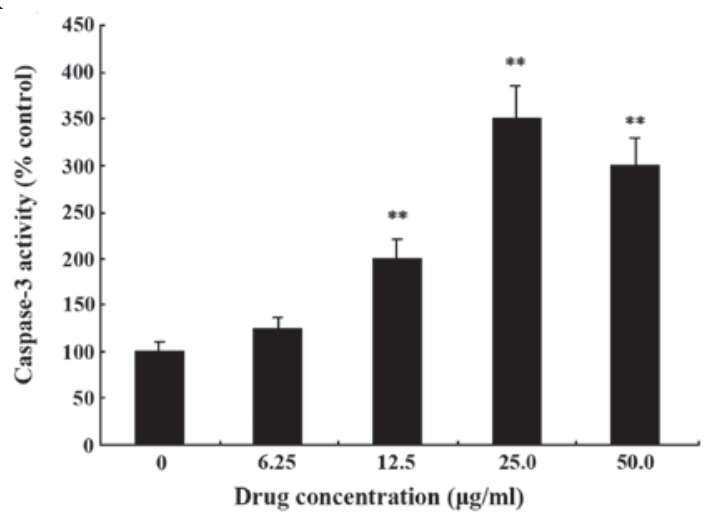

B
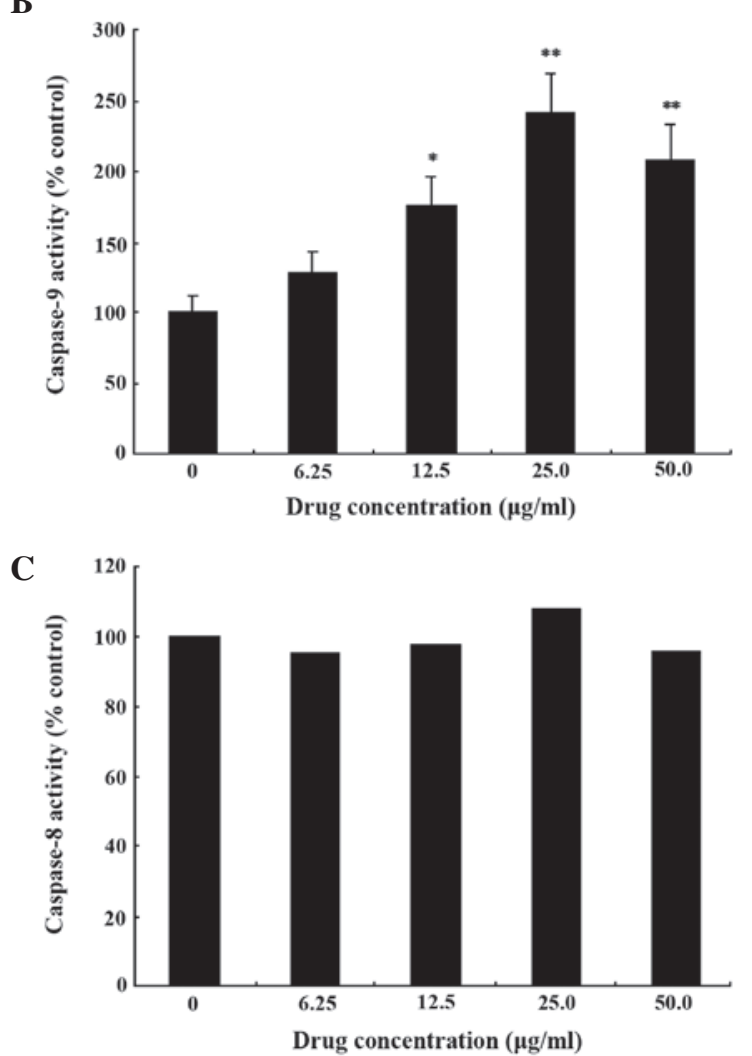

Figure 6. Detection of the activity of (A) caspase-3, (B) caspase-9 and (C) caspase-8 in SMMC-7721 cells following treatment with various concentrations of gallic acid for $48 \mathrm{~h}$. Data are expressed as the mean \pm standard deviation of three independent experiments. ${ }^{*} \mathrm{P}<0.05,{ }^{* *} \mathrm{P}<0.01$, vs. control group. have been demonstrated to exhibit anticancer effects in various in vitro and in vivo cancer models (31). Among them, GA has been identified as a significant active component of certain herbal medicinal plants, which exhibit growth inhibitory effects on various cancer cell lines $(20,32,33)$. In the present study, the antiproliferative effects of GA on HepG2 and SMMC-7721 cells were initially examined. The MTT assay results revealed that GA exhibited marked cytotoxicity against HepG2 and SMMC-7721 cells in a time- and concentration-dependent manner, based on the low $\mathrm{IC}_{50}$ values determined. In addition, drugs that selectively target cancer cells, and thus exert little effect on healthy cells, are significant for improvements to cancer therapies. In order to determine whether GA exhibited selective cytotoxic activity for HepG2 and SMMC-7721 cells, the present study compared the effects of GA on HL-7702 normal hepatocyte cells, with the effects on HepG2 and SMMC-7721 cells. The results revealed that the $\mathrm{IC}_{50}$ value was $80.9 \pm 4.6 \mu \mathrm{g} / \mathrm{ml}$ for $\mathrm{HL}-7702$ cells at $48 \mathrm{~h}$. This value was 3 -fold higher than the $\mathrm{IC}_{50}$ value observed in HCC cells, suggesting that GA may not affect normal/healthy cells, thus warranting further in vivo studies regarding the use of GA.

Anticancer drugs are often capable of inducing apoptosis, therefore eliminating cells that harbor genetic damage or exhibit inappropriate division (34). During apoptosis, a physiological process required for the normal development and maintenance of tissue homeostasis, morphological changes may be observed. These include chromatin condensation, DNA fragmentation, cytoplasm shrinkage and apoptotic body formation $(21,35)$. To elucidate the underlying mechanisms of the anticancer effects of GA, the present study used Giemsa and acridine orange staining, DNA fragmentation and Annexin V-FITC/PI double staining to investigate potential apoptosis-inducing properties. GA-treated SMMC-7721 cells demonstrated significant apoptosis-associated morphological alterations, including chromatin condensation and DNA fragmentation. Furthermore, flow cytometric analysis revealed that, the early and late apoptotic cell proportions increased alongside increasing GA concentration. These results suggested that SMMC-7721 cells treated with GA followed the typical apoptotic pathway.

There are two primary, linked apoptotic pathways: The death receptor (extrinsic) pathway and the 
A

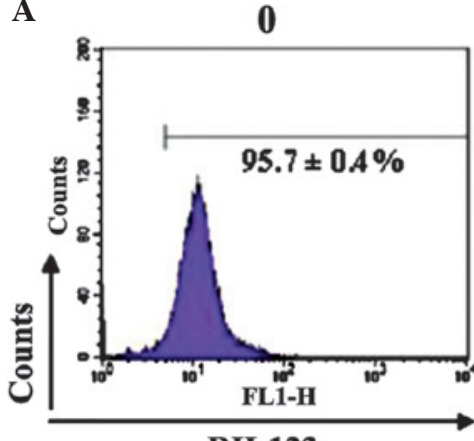

RH-123

B

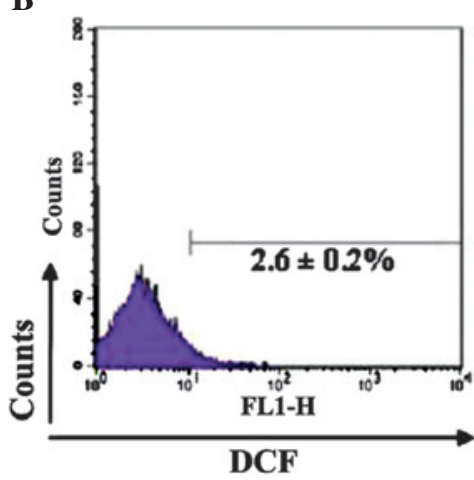

6.25
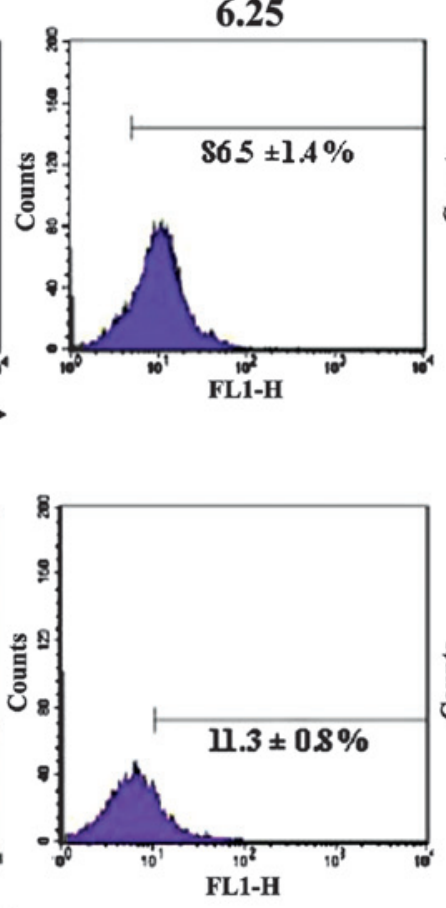

12.5
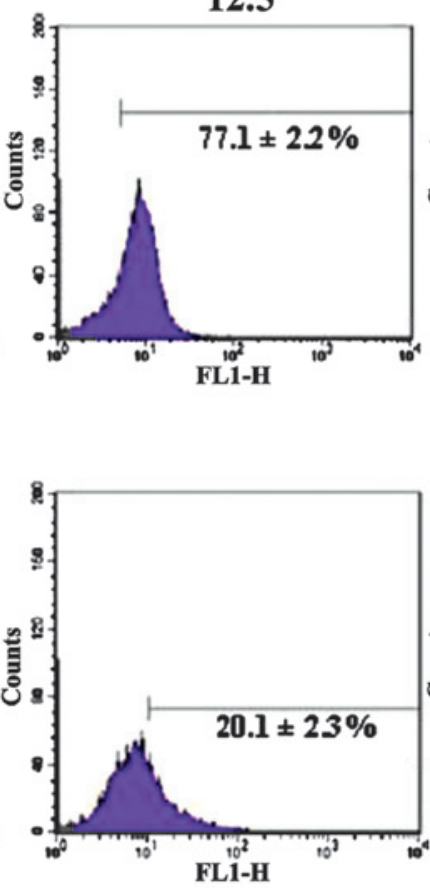

25.0

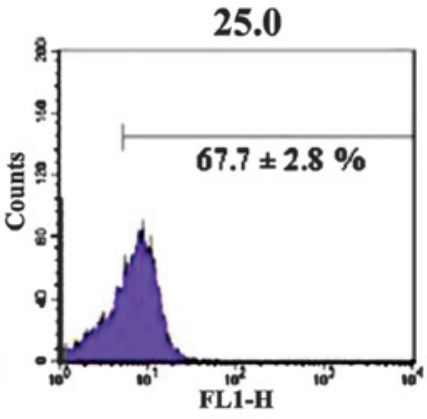

Figure 7. Flow cytometric analysis of SMMC-7721 cells following treatment with various concentrations of GA. (A) Mitochondrial membrane potential and (B) the generation of ROS in SMMC-7721 cells following treatment with various concentrations of GA. Data are expressed as the mean \pm standard deviation. RH-123, rhodamine 123; DCF, 2,7-dichlorfluorescein; ROS, reactive oxygen species; GA, gallic acid.

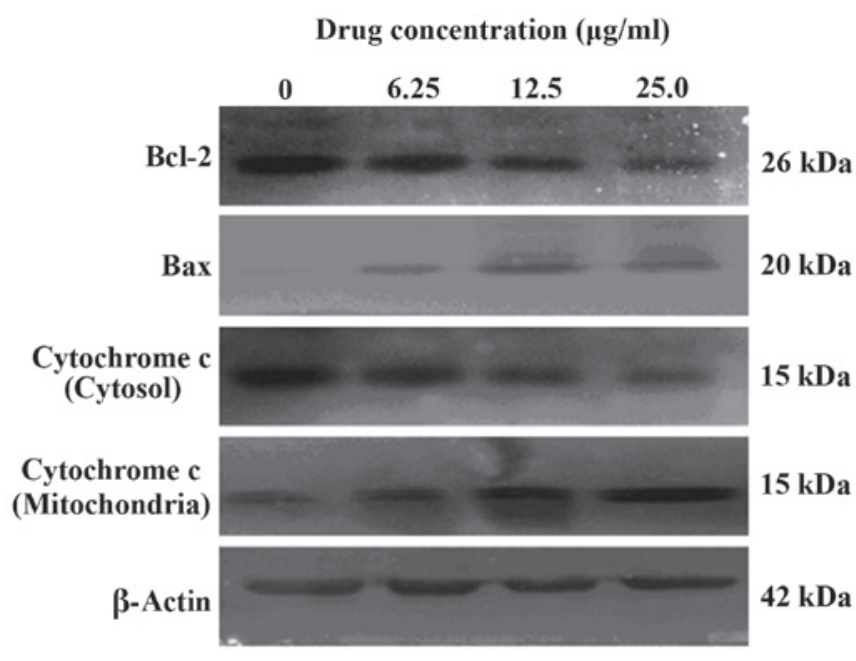

Figure 8. Western blot analysis of apoptosis associated proteins Bax, Bcl-2 and cytochrome $c$. Equal quantities of cellular protein were separated by $12 \%$ SDS-PAGE and transferred onto polyvinylidene difluoride membranes. $\beta$-actin served as a control. Bcl-2, B-cell lymphoma-2; Bax, Bcl-2-like protein 4 .

mitochondrial-mediated (intrinsic) pathway (36). A significant mediator of apoptosis is the caspase family, which are expressed as proenzymes (37). Following activation, caspases initiate cell death via inactivation of anti-apoptotic proteins, prevention of DNA replication and cytoskeletal reorganization. Caspase-3 has a significant role in apoptosis, and upstream regulators, including caspase -8 and -9 control its activity. Caspase -8 and -9 modulate the extrinsic and intrinsic apoptotic pathways, respectively $(38,39)$. The present study therefore measured the activity of caspase-3, -8 and -9 in SMMC-7721 cells following treatment with GA. It was revealed that GA induced a two- to three-fold dose-dependent activation of caspase- 3 and -9 , however no marked increase in caspase- 8 activity was observed. These results indicated that GA may induce apoptosis in SMMC-7721 cells via activation of the mitochondrial pathway. MMP has a significant role in the maintenance of physiological functioning in the electron transport chain, for the generation of adenosine triphosphate in cells (40). Caspase activation is primarily initiated by alteration of the MMP (27). The present study therefore investigated the MMP of SMMC-7721 cells following treatment with GA. The reduced density of RH-123 fluorescence observed following treatment with GA indicated that there was an increased proportion of cells with disrupted mitochondrial membranes in SMMC-7721 cells. This observation confirmed that the apoptosis of SMMC-7721 cells induced by GA may occur via the mitochondrial-mediated pathway.

In the mitochondrial-mediated apoptotic pathway, the release of cytochrome $c$ from mitochondria is a significant event (41). In healthy cells, cytochrome $c$ is located in the space between the inner and outer mitochondrial membranes, however it is released into the cytosol during apoptosis (42). The activation of downstream caspases is triggered by the formation of the apoptotic protease activating factor-1 (Apaf-1)/cytochrome $c$ complex and the activation of pro-caspase-9. Cytochrome $c$ also has a significant role in the electron transport chain, which generates an electrochemical potential across the mitochondrial membrane, known as the MMP $(43,44)$. The results of the present study demonstrated that cytochrome $c$ was released from mitochondria into the 
cytosol in SMMC-7721 cells treated with GA. This result correlated with the results of the MMP measurement investigation, and further indicated that GA is capable of inducing apoptosis of SMMC-7721 cells via the mitochondrial-mediated pathway.

ROS, including oxygen ions and peroxides, are chemically reactive molecules, which may arise during periods of environmental stress (45). ROS have a significant role in oxidative stress, and are generated as by-products of cellular metabolism, typically in mitochondria (46). The elevated production of ROS in mitochondria leads to loss of the MMP, and an increase in the rate of release of cytochrome $c$ from damaged mitochondria $(27,34,47)$. In addition, the results of the present study indicated that the generation of ROS following GA treatment appeared to be dose-dependent.

Proteins of the Bcl-2 family have been suggested to be the primary regulators of apoptosis in the mitochondrial-mediated pathway (48). Bcl-2 is an anti-apoptotic protein, while Bax is a critical pro-apoptotic and tumor suppressor protein. Bax is able to increase the permeability of mitochondrial membranes and accelerate apoptotic cell death $(49,50)$. The results of the present study demonstrated that GA downregulated $\mathrm{Bcl}-2$ expression and upregulated Bax expression. Bax protein is inserted into the outer membrane of the mitochondrion and forms a channel, allowing cytochrome $c$ to pass into the cytoplasm (51). The aforementioned findings indicated that the apoptosis of SMMC-7721 cells induced by GA occurred via the mitochondrial-mediated pathway.

Taken together, the results of the present study demonstrate that GA induced apoptosis in SMMC-7721 cells through the mitochondrial-mediated pathway. It was therefore hypothesized that apoptosis was induced as follows: ROS were generated at the induction of apoptosis. Subsequently, electron transport was disrupted and the MMP was decreased in SMMC-7721 cells. Bax protein expression was upregulated and Bax was inserted into the outer mitochondrial membrane to form channels, facilitating the release of cytochrome $c$ from mitochondria into the cytoplasm. Cytochrome $c$ integrated with Apaf-1 and pro-caspase-9, which activated caspase-9 and subsequently caspase-3. Caspase-3 induced cytoplasm shrinkage, membrane blebbing, chromatin condensation and DNA fragmentation in SMMC-7721 cells.

In conclusion, GA is capable of inhibiting the growth of HepG2 and SMMC-7721 HCC cells, as well as inducing apoptosis in SMMC-7721 cells in vitro. On the basis of these results, it was suggested that GA may have the potential to be a novel compound for the treatment of HCC. However, further studies are required to elucidate the precise molecular mechanisms underlying the effects of GA on growth inhibition and apoptosis induction in HCC, and assess the anti-tumor activity in animal models, prior to the application of the present results to the treatment of human HCC.

\section{Acknowledgements}

The present study was supported by the Wu Jieping Medical Foundation (grant no. LDWMF-P5-2011B004). Equipment support for FCM was provided by Changchun Institute of Applied Chemistry (Chinese Academy of Sciences, Changchun, China). The authors would also like to thank Dr Zuojia Liu for significant advice on this study.

\section{References}

1. Parkin DM, Bray F, Ferlay J and Pisani P: Global cancer statistics, 2002. CA Cancer J Clin 55: 74-108, 2005.

2. Jemal A, Siegel R, Ward E, Hao Y, Xu J and Thun MJ: Cancer statistics, 2009. CA Cancer J Clin 59: 225-249, 2009.

3. Asia-Pacific Working Party on Prevention of Hepatocellular Carcinoma: Prevention of hepatocellular carcinoma in the Asia-Pacific region: Consensus statements. J Gastroenterol Hepatol 25: 657-663, 2010.

4. Yuen MF, Hou JL and Chutaputti A: Asia pacific working party on prevention of hepatocellular carcinoma: Hepatocellular carcinoma in the Asia pacific region. J Gastroenterol Hepatol 24: 346-353, 2009.

5. Han LL, Lv Y, Guo H, Ruan ZP and Nan KJ: Implications of biomarkers in human hepatocellular carcinoma pathogenesis and therapy. World J Gastroenterol 20: 10249-10261, 2014.

6. Hernandez-Gea V, Turon F, Berzigotti A and Villanueva A: Management of small hepatocellular carcinoma in cirrhosis: Focus on portal hypertension. World J Gastroenterol 19: 1193-1199, 2013

7. Trevisani F, Cantarini MC, Wands JR and Bernardi M: Recent advances in the natural history of hepatocellular carcinoma. Carcinogenesis 29: 1299-1305, 2008.

8. Chen D, Yao WJ, Zhang XL, Han XQ, Qu XY, Ka WB, Sun DG, $\mathrm{Wu} \mathrm{XZ}$ and Wen ZY: Effects of Gekko sulfated polysaccharide-protein complex on human hepatoma SMMC-7721 cells: Inhibition of proliferation and migration. J Ethnopharmacol 127: 702-708, 2010.

9. Luo KW, Sun JG, Chan JY, Yang L, Wu SH, Fung KP and Liu FY: Anticancer effects of imperatorin isolated from Angelica dahurica: Induction of apoptosis in HepG2 cells through both death-receptor- and mitochondria-mediated pathways. Chemotherapy 57: 449-459, 2011.

10. Zhao WJ, Niu FL, Li J, Dong Q and Huang ZY: Components of volatile oil from water-caltrop and their anti-tumor effect in vitro. Chem Res Chinese Universities 25: 56-59, 2009.

11. Kim SH, Jun CD, Suk K, Choi BJ, Lim H, Park S, Lee SH, Shin HY, Kim DK and Shin TY: Gallic acid inhibits histamine release and pro-inlammatory cytokine production in mast cells. Toxicol Sci 91: 123-131, 2006.

12. Li D, Liu ZJ, Zhao WJ, Xi Y and Niu F: A straightforward method to determine the cytocidal and cytopathic effects of the functional groups of gallic acid. Process Biochemistry 46: 2210-2214, 2011 .

13. Kim SW, Han YW, Lee ST, Jeong HJ, Kim SH, Kim IH, Lee SO, Kim DG, Kim SH, Kim SZ and Park WH: A superoxide anion generator, pyrogallol, inhibits the growth of HeLa cells via cell cycle arrest and apoptosis. Mol Carcinog 47: 114-125, 2008.

14. Kratz JM, Andrighetti-Fröhner CR, Leal PC, Nunes RJ, Yunes RA, Trybala E, Bergström T, Barardi CR and Simões CM: Evaluation of anti-HSV-2 activity of gallic acid and pentylgallate. Biol Pharm Bull 31: 903-907, 2008.

15. Kang MS, Oh JS, Kang IC, Hong SJ and Choi CH: Inhibitory effect of methyl gallate and gallic acid on oral bacteria. J Microbiol 46: 744-750, 2008.

16. Inoue M, Suzuke R, Koide T, Sakaguchi N, Ogihara Y and Yabu Y: Antioxidant, gallic acid, induces apoptosis in HL-60RG cells. Biochem Biophys Res Commun 204: 898-904, 1994.

17. Inoue M, Suzuke R, Sakaguchi N, Li Z, Takeda T, Ogihara Y, Jiang BY and Chen Y: Selective induction of cell death in cancer cells by gallic acid. Bio Pharm Bull 18: 1526-1530, 1995.

18. Kawada M, Ohno Y, Ri Y, Ikoma T, Yuugetu H, Asai T, Watanabe M, Yasuda N, Akao S, Takemura G, et al: Anti-tumor effect of gallic acid on LL-2 lung cancer cells transplanted in mice. Anticancer Drugs 12: 847-852, 2001

19. Madlener S, Illmer C, Horvath Z, Saiko P, Losert A, Herbacek I, Grusch M, Elford HL, Krupitza G, Bernhaus A, et al: Gallic acid inhibits ribonucleotide reductase and cyclooxygenases in human HL-60 promyelocytic leukemia cells. Cancer Lett 245: 156-162, 2007.

20. Kaur M, Velmurugan B, Rajamanickam S, Agarwal R and Agarwal C: Gallic acid, an active constituent of grape seed extract, exhibits anti-proliferative, pro-apoptotic and anti-tumorigenic effects against prostate carcinoma xenograft growth in nude mice. Pharm Res 26: 2133-2140, 2009.

21. Ding X, Zhu FS, Li M and Gao SG: Induction of apoptosis in human hepatoma SMMC-7721 cells by solamargine from Solanum nigrum L. J Ethnopharmacol 139: 599-604, 2012. 
22. Li D, Liu Z, Zhao W, Zheng X, Wang J and Wang E: A small-molecule induces apoptosis and suppresses metastasis in pancreatic cancer cells. Eur J Pharm Sci 48: 658-667, 2013.

23. Zhao W, Li D, Liu Z, Zheng X, Wang J and Wang E: Spiclomazine induces apoptosis associated with the suppression of cell viability, migration and invasion in pancreatic carcinoma cells. PLoS One 8: e66362, 2013

24. Babich H, Zuckerbraun HL, Ricklis AS and Blau L: In vitro toxicity of sodium nitroprusside to human endothelial ECV304 cells. Environ Toxicol Pharmacol 5: 135-144, 1998.

25. Hu YW, Liu CY, Du CM, Zhang J, Wu WQ and Gu ZL: Induction of apoptosis in human hepatocarcinoma SMMC-7721 cells in vitro by flavonoids from Astragalus complanatus. J Ethnopharmacol 123: 293-301, 2009.

26. Banerjee S, Kaseb AO, Wang Z, Kong D, Mohammad M, Padhye S, Sarkar FH and Mohammad RM: Antitumor activity of gemcitabine and oxaliplatin is augmented by thymoquinone in pancreatic cancer. Cancer Res 69: 5575-5583, 2009.

27. Zhou YJ, Zhang SP, Liu CW and Cai YQ: The protection of selenium on ROS mediated-apoptosis by mitochondria dysfunction in cadmium-induced LLC-PK(1) cells. Toxicol In Vitro 23: 288-294, 2009.

28. Arbab IA, Looi CY, Abdul AB, Cheah FK, Wong WF, Sukari MA, Abdullah R, Mihan S, Syam S, Arya A, et al: Dentatin induces apoptosis in prostate cancer cells via Bcl-2, Bcl-xL, Survivin downregulation, Caspase-9, -3/7 Activation, and NF- $\kappa \mathrm{B}$ Inhibition. Evid Based Complement Alternat Med 2012: 856029, 2012.

29. Zhang YQ, Xiao CX, Lin BY, Shi Y, Liu YP, Liu JJ, Guleng B and Ren JL: Silencing of Pokemon enhances caspase-dependent apoptosis via fas- and mitochondria-mediated pathways in hepatocellular carcinoma cells. PloS One 8: e68981, 2013.

30. Wu M, Zhang H, Hu J, Weng Z, Li C, Li H, Zhao Y, Mei X, Ren F and $\mathrm{Li} \mathrm{L}$ : Isoalantolactone inhibits UM-SCC-10A cell growth via cell cycle arrest and apoptosis induction. PloS One 8: e76000, 2013

31. Nishino H, Satomi Y, Tokuda H and Masuda M: Cancer control by phytochemicals. Curr Pharm Des 13: 3394-3399, 2007.

32. Choi KC, Lee YH, Jung MG, Kwon SH, Kim MJ, Jun WJ, Lee J, Lee JM and Yoon HG: Gallic acid suppresses lipopolysaccharide-induced nuclear factor-kappaB signaling by preventing RelA acetylation in A549 lung cancer cells. Mol Cancer Res 7: 2011-2021, 2009

33. Chen HM, Wu YC, Chia YC, Chang FR, Hsu HK, Hsieh YC, Chen CC and Yuan SS: Gallic acid, a major component of Toona sinensis leaf extracts, contains a ROS-mediated anti-cancer activity in human prostate cancer cells. Cancer Lett 286: 161-171, 2009.

34. You BR, Moon HJ, Han YH and Park WH: Gallic acid inhibits the growth of HeLa cervical cancer cells via apoptosis and/or necrosis. Food Chem Toxicol 48: 1334-1340, 2010

35. Oazi A, Pal J, Maitah M, Fulciniti M, Pelluru D, Nanjappa P, Lee S, Batchu RB, Prasad M, Bryant CS, et al: Anticancer activity of a broccoli derivative, sulforaphane, in barrett adenocarcinoma: Potential use in chemoprevention and as adjuvant in chemotherapy. Transl Oncol 3: 389-399, 2010.
36. Yang L, Wang P, Wang H, Li Q, Teng H, Liu Z, Yang W, Hou L and Zou X: Fucoidan derived from Undaria pinnatifida induces apoptosis in human hepatocellular carcinoma SMMC-7721 cells via the ROS-mediated mitochondrial pathway. Mar Drugs 11: 1961-1976, 2013

37. Chen L, Gong MW, Peng ZF, Zhou T, Ying MG, Zheng QH, Liu QY and Zhang QQ: The marine fungal metabolite, dicitrinone B, induces A375 cell apoptosis through the ROS-related caspase pathway. Mar Drugs 12: 1939-1958, 2014.

38. Cryns V and Yuan J: Proteases to die for. Gene Dev 12: 1551-1570, 1998.

39. Turk B, Stoka V, Rozman-Pungercar J, Cirman T, Droga-Mazovec G, Oresić K and Turk V: Apoptotic pathways: Involvement of lysosomal proteases. Biol Chem 383: 1035-1044, 2002.

40. Joshi DC and Bakowska JC: Determination of mitochondrial membrane potential and reactive oxygen species in live rat cortical neurons. J Vis Exp 23: 2704, 2011.

41. Reed JC and Green DR: Remodeling for demolition: Changes in mitochondrial ultrastructure during apoptosis. Mol Cell 9: 1-3, 2002.

42. Bos JL: Ras oncogenes in human cancer: A review. Cancer Res 49: 4682-4689, 1989

43. Hu Y, Benedict MA, Ding L and Núñez G: Role of cytochrome $c$ and dATP/ATP hydrolysis in Apaf-1-mediated caspase-9 activation and apoptosis. EMBO J 18: 3586-3595, 1999.

44. Goldstein JC, Waterhouse NJ, Juin P, Evan GI and Green DR: The coordinate release of cytochrome $c$ during apoptosis is rapid, complete and kinetically invariant. Nat Cell Biol 2: 156-162, 2000.

45. Devasagayam TP, Tilak JC, Boloor KK, Sane KS, Ghaskadbi SS and Lele RD: Free radicals and antioxidants in human health: Current status and future prospects. J Assoc Physicians India 52: 794-804, 2004

46. Devasagayam TP, Tilak JC, Boloor KK, Sane KS, Ghaskadbi SS and Lele RD: Free radicals and antioxidants in human health: Current status and future prospects. J Assoc Physicians India 52: 794-804, 2004

47. You BR and Park WH: Gallic acid-induced lung cancer death is related to glutathione depletion as well as reactive oxygen species increase. Toxicol In Vitro 24: 1356-1362, 2010.

48. Renault TT, Teijido O, Antonsson B, Dejean LM and Manon S: Regulation of Bax mitochondrial localization by Bcl-2 and Bcl-x(L): Keep your friends close but your enemies closer. Int J Biochem Cell Biol 45: 64-67, 2013.

49. Tsujimoto Y and Shimizu S: Bcl-2 family: Life-or-death switch. FEBS Lett 466: 6-10, 2000.

50. Yamaguchi $\mathrm{H}$, Bhalla $\mathrm{K}$ and Wang $\mathrm{HG}$ : Bax plays a pivotal role in thapsigargin-induced apoptosis of human colon cancer HCT116 cells by controlling Smac/Diablo and Omi/HtrA2 release from mitochondria. Cancer Res 63: 1483-1489, 2003.

51. Wang W, Zhao $\mathrm{CH}$, Zhang $\mathrm{N}$ and Wang J: Vitamin D analog EB1089 induces apoptosis in a subpopulation of SGC-7901 gastric cancer cells through a mitochondrial-dependent apoptotic pathway. Nutr Cancer 65: 1067-1075, 2013. 